\title{
Calidad Sanitaria de las Aguas Superficiales y Subterráneas, de la Subcuenca del Río Viejo
}

Carmen Chacón y Helen García

Centro para la Investigación en Recursos Acuáticos de Nicaragua, CIRA/UNAN-Managua. carmen.chacon@cira-unan.edu.ni, helen.garcia@cira-unan.edu.ni

\section{RESUMEN}

Se estudió la calidad sanitaria, de las aguas superficiales y subterráneas de la Subcuenca del Río Viejo, durante la época seca (Marzo 2010) y la época lluviosa (Enero 2011). El estudio, se basó en el análisis de organismos Coliformes termotolerantes, Escherichia coli, Estreptococos fecales y Enterococos. De los dieciséis sitios de muestreo examinados, en el Río Viejo y sus tributarios, solamente dos, Lago Apanás y Abra Vieja se encontraron aptos para el uso recreacional. Los Coliformes termotolerantes y Escherichia coli, fueron consistentemente detectadas en ambas épocas de estudio. De los siete manantiales estudiados, solamente La Pacaya, para la época seca y El Pavón, para la época de lluvias, se encontraron aptos para el consumo. En cuanto a los pozos perforados (10 en total), Santa Rosa y Tatascame, para época seca y Namanji, Los Arados y Santa Bárbara, para la época de lluvias, pueden ser utilizados con fines de consumo. Los demás, excedieron los criterios de la W.H.O, 2011, para que éstos puedan ser usados con fines de consumo. Las concentraciones bacterianas, detectadas en los pozos excavados ( 3 en total) indican que éstos se encuentran expuestos a contaminación por residuos orgánicos de origen humano y animal, resultando ser no aptos para consumo. Los resultados obtenidos evidencian que las aguas superficiales y subterráneas, están siendo influenciadas por actividades de origen antrópicas y que existe una contaminación de origen fecal, que representa un riesgo potencial a la salud de la población.

Palabras Claves: Subcuenca del Río Viejo, Coliformes, Escherichia coli, Enterococos.

\section{INTRODUCCIÓN}

A raíz de las afectaciones del Huracán Mitch, la Agencia Canadiense de Desarrollo Internacional (ACDI) decidió apoyar la reconstrucción de la región Central-Norte del país, formulando el Proyecto Integral de Manejo de Cuencas Hidrográficas, Agua y Saneamiento (PIMCHAS), como una iniciativa de desarrollo de capacidades, sistemas y recursos para hacerse cargo de la agenda de desarrollo. (www.marena.gob).

En el mes de Octubre 2006, los Gobiernos de Nicaragua y Canadá firmaron un memorando de entendimiento para implementar el proyecto PIMCHAS, con el objetivo de mejorar la calidad de vida y el bienestar de los habitantes de la zona Norte de Nicaragua. (www.marena.gob) MARENA-PIMCHAS se enmarca en las prioridades que ha definido el Gobierno de Reconciliación y Unidad Nacional con acciones de protección y recuperación de las fuentes de agua, preparación de planes de manejo integral de cuencas, implementación de acciones de prevención y control de la contaminación ambiental por la mala disposición de aguas residuales, mal manejo de basura y uso de plaguicidas, y el fomento a la adopción de buenas prácticas agrícolas y trabajando en defensa del medio ambiente. (www.marena.gob)

Con este propósito, se construyó la alianza entre el Centro para la Investigación en Recursos Acuáticos de Nicaragua (CIRA/UNAN-Managua) y el Programa MARENA - PIMCHAS. Este convenio contempla el diseño y ejecución de proyectos de investigación, relacionados a problemas de calidad de agua y gestión de cuencas. Partiendo de lo anterior, se evaluó la calidad sanitaria de las aguas superficiales y subterráneas de la Subcuenca del Río Viejo, en la estación seca del año 2010 y la lluviosa del 2011.

La contaminación fecal ha sido, y sigue siendo, el principal riesgo sanitario en el agua, porque supone la incorporación de microorganismos patógenos procedentes de enfermos y portadores, y la transmisión hídrica a la población susceptible. Por ello el control sanitario de riesgos microbiológicos es tan importante, y constituye una medida sanitaria básica para mantener un grado de salud adecuado en la población.

El riesgo de contaminación tanto a nivel humano, como ambiental hace necesario el control de la presencia de microorganismos en el agua. Determinar las bacterias indicadoras presentes y su concentración, proporciona herramientas indispensables para conocer la calidad del agua y para la toma de decisiones en relación al control de vertidos, tratamiento de aguas y conservación de ecosistemas. Con base a estas consideraciones se evaluaron las aguas superficiales y subterráneas (Río Viejo y tributarios más importantes, manantiales, pozos 
perforados y algunos pozos excavados), de la Subcuenca del Río Viejo.

\section{MATERIALES Y MÉTODOS}

Para el estudio se realizaron dos campañas de muestreo (época seca, Marzo 2010 y época lluviosa, Enero 2011). Se seleccionaron 16 sitios de muestreo a lo largo del Río Viejo, 7 manantiales, 10 pozos perforados y 3 pozos excavados en el área de estudio. Para evaluar la calidad bacteriológicas de las aguas se utilizaron Coliformes termotolerantes, Escherichia coli, Estreptococos fecales y Enterococos.

Las muestras de agua fueron analizadas inmediatamente después de su recolección, según la metodología de APHA, Standard Methods (2005), aplicando la técnica de Fermentación en Tubos Múltiples (FTM) y los resultados fueron expresados como NMP/100 ml.

\section{RESULTADOS Y DISCUSIÓN}

\section{Aguas Superficiales de la Subcuenca del Río Viejo Coliformes termotolerantes}

Las concentraciones bacterianas de Coliformes termotolerantes, en todos los sitios estudiados (16 en total) durante la época seca (marzo 2010) y la época lluviosa (enero, 2011) fluctuaron entre 1.10 x 101 y $7.90 \mathrm{x}$ 104 NMP.100 ml-1. (fig.1) Las máximas concentraciones fueron dadas por Trinidad (Casco Urbano) y Trinidad (Las Lajas) con concentraciones de 7.90 x $10_{4}$ y 2.40 x 104 NMP.100 ml-1, respectivamente (ver figura.1). Las altas concentraciones de Coliformes termotolerantes en estos sitios se vinculan directamente con el vertido de aguas residuales domésticas, sin previo tratamiento; Csuros \& Csuros (1999) platea que la presencia de números significativos de Coliformes, evidencian que el agua está contaminada con material fecal y algunos patógenos que son eliminados a través de las heces, también pueden estar presentes.

Los sitios denominados Jordán, Lago Apanás, La Perla y Abra Vieja, fueron los que presentaron las mínimas concentraciones, en ambas épocas de estudio (1.10 x 101$1.30 \times 10_{2}$ NMP.100 ml-1). (ver figura1). Durante ambas épocas de estudio se observó la presencia constante de Coliformes termotolerantes.

A excepción del Jordán, Lago Apanas, La Perla y Abra Vieja, las concentraciones detectadas en los otros sitios estudiados excedieron el valor guía establecido por la EPA (1986) para el uso recreacional.

Según esta, para el contacto directo y prolongado (ejemplo natación), las concentraciones bacterianas de Coliformes termotolerantes, no deben exceder de $2.00 \mathrm{x}$ $10_{2}$ NMP.100 ml-1. Además, en estos lugares superan el valor máximo admisible para aguas destinadas a la irrigación. Las normas canadienses establecen como concentraciones máximas tentativas, 100 Coliformes fecales (termotolerantes) $/ 100 \mathrm{ml}$.

\section{Escherichia coli}

Las concentraciones bacterianas de E. coli durante ambas épocas de estudio oscilaron entre $<1.8$ y 7.90 x $10_{4}$ NMP.100 ml-1 (fig.1). Las máximas concentraciones fueron presentadas por Trinidad Casco Urbano y Trinidad Las Lajas 7.90 x $10_{4}$ y 2.40 x $10_{4}$ NMP. 100 ml-1 respectivamente. (ver figura1).

Durante las dos épocas de estudio se observó la presencia constante de E.coli en todos los sitios examinados. Según APHA (1999) la presencia de E.coli en el agua es indicativo de contaminación fecal, por lo que la presencia de esta en los ríos, evidencia una contaminación por residuos orgánicos de origen fecal.

Los sitios denominados Jordán, Lago Apanas, La Perla y Abra Vieja, fueron los que presentaron las concentraciones más bajas en ambas épocas (< 1.8 4.90x10 1 NMP.100 ml-1). (ver figura1). Sin embargo, los otros sitios examinados presentaron densidades de E.coli superiores al límite establecido por la agencia de protección ambiental de los Estados Unidos (U.S. EPA, 1986). Según este organismo, para aguas recreacionales, las densidades de E. coli no deben de exceder las 126 colonias de E. coli / $100 \mathrm{ml}$.

Partiendo de los resultados obtenidos y al hecho que algunas cepas de E. coli pueden causar enfermedades, se puede afirmar que todos los sitios estudiados (aguas superficiales) en la Subcuenca del Río Viejo, representan un foco de contaminación y un riesgo a la salud humana, en casos que la población entre en contacto con el agua contaminada.

\section{Estreptococos Fecales}

Durante el período de muestreo que corresponde a la época seca (Marzo 2010) se estudió la presencia del grupo Estreptococos fecales, para determinar el grado de polución fecal, del Río Viejo y algunos tributarios. El hábitat normal de los Estreptococos fecales es el tracto gastrointestinal de los animales de sangre caliente; estos han sido utilizados junto con los Coliformes fecales para diferenciar contaminación fecal humana de otros animales de sangre caliente. (APHA, 1999)

Los Estreptococos fecales se detectaron en todos los sitios de muestreo, en concentraciones que oscilaron entre 4.5 y 2.40 x $104 \mathrm{NMP} .100 \mathrm{ml}$-1. Con una máxima de $2.40 \times 104$ NMP.100 ml-1para Trinidad Casco Urbano y mínimas de 4.50 x 100 y 3.30 x $10_{1}$ NMP. 100 ml-1. Para Lago Apanás y Abra Vieja, respectivamente (ver 
figura1). A excepción de Lago Apanás y Abra Vieja, todos los sitios (14 en total) estudiados excedieron el valor guía para aguas destinadas a la recreación, la EEC (1976) establece como valor máximo admisible $1.00 \mathrm{x}$ 102 NMP. 100 ml-1.

Melonicsa) y $2.40 \times 103$ NMP.100 ml-1 (Trinidad Casco Urbano) para la época de invierno (enero 2011) (fig.1). A excepción de Los Encuentros, Santa Rosa, Trinidad Casco Urbano y Calpules, los otros sitios examinados cumplen con el valor máximo admisible establecido para aguas naturales destinadas a la recreación. APHA, 1999

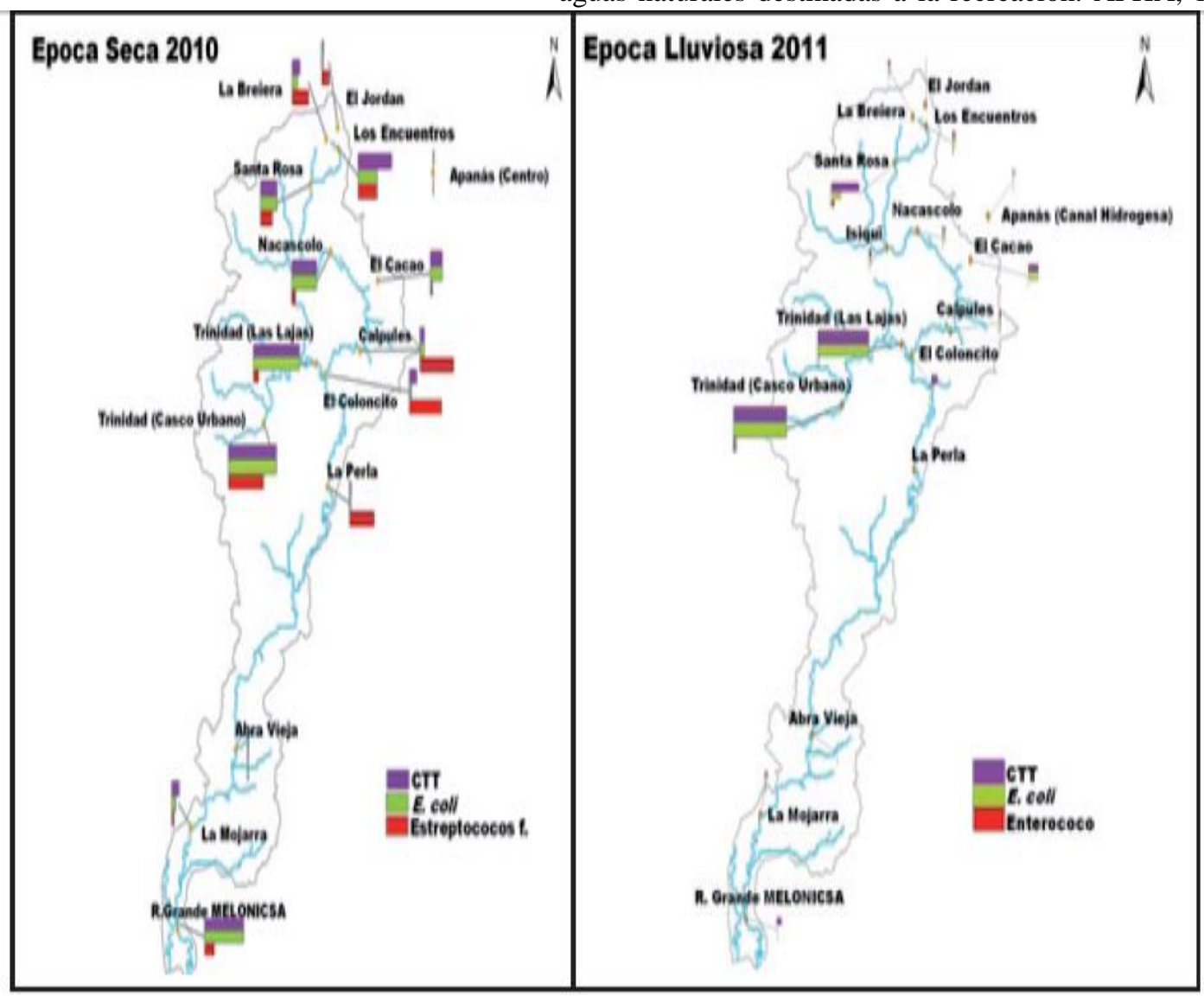

Figura 1. Indicadores de contaminación bacteriológica, en el Río Viejo y sus Tributarios para Marzo 2010 y Enero 2011.

Los resultados obtenidos indican contaminación con materia orgánica de origen animal, probablemente relacionada al hecho de que en su mayoría, estos sitios, son transitados rutinariamente por ganado.

\section{Enterococos}

El grupo de los Enterococos es un subgrupo de los Estreptococos fecales que incluyen $S$. faecalis, $S$. faecium, S. gallinarum y S. avium. Los Enterococos son considerados valiosos indicadores bacterianos para determinar el grado de contaminación fecal de aguas superficiales destinadas a la recreación (APHA, 1999) de ahí la importancia de su estudio en las aguas superficiales de la Subcuenca del Río Viejo.

Las concentraciones de Enterococos fecales oscilaron entre $2.00 \times 100$ (Nacascolo, Lago Apanás, R. Grande menciona como valor máximo admisible 33 Enterococos $/ 100 \mathrm{ml}$ para aguas dulces que van a ser utilizadas en la recreación.

\section{Aguas Subterráneas de la Subcuenca del Río Viejo Manantiales}

En vista que los manantiales de la Subcuenca Río Viejo, representan una fuente de agua para el consumo de la población, y que la calidad sanitaria de los mismos es de vital importancia para la salud de los consumidores, se seleccionaron un total de 7 manantiales representativos del agua subterránea de esta zona.

Los resultados obtenidos mostraron una polución difusa de las aguas subterráneas (manantiales) examinadas. Para la época seca, La Pacaya fue el único apto para el consumo, cinco de los siete manantiales estudiados 
presentaron concentraciones bacterianas de Coliformes termotolerantes y Escherichia coli, que exceden el valor guía establecido, para aguas que van a ser destinadas al consumo, con densidades bacterianas que fluctuaron entre $2.00 \times 10_{0}$ y $1.30 \times 10_{2}$ NMP. $100 \mathrm{ml}-1$. (ver figura 2 ).

En época de lluvias, El Pavón fue el único apto para el consumo, seis de los siete manantiales, excedieron el valor guía, con concentraciones que oscilaron entre Figura 2. Indicadores de contaminación bacteriológica, en los manantiales analizados en la Subcuenca del Río Viejo para Marzo 2010 y Enero 2011.
Pacaya y Yagualica, con concentraciones que oscilaron entre <1.8 y 4.60x102 NMP.100 ml-1. (fig. 2), según Csuros \& Csuros, 1999 la presencia de Estreptococos fecales en el agua verifica una polución de origen fecal. Contrario a las concentraciones de Estreptococos fecales, los Enterococos estudiados en la época de lluvias, estuvieron débilmente representados (<1.8 y 6.00 x 100 NMP.100 ml-1). De los siete manantiales examinados solamente El Zapote, La Breiera y Yagualica, mostraron la presencia de éstos con concentraciones que fluctuaron entre 4.00 y 6.00 x $10_{0}$ NMP.100 ml-1. (ver figura 2).

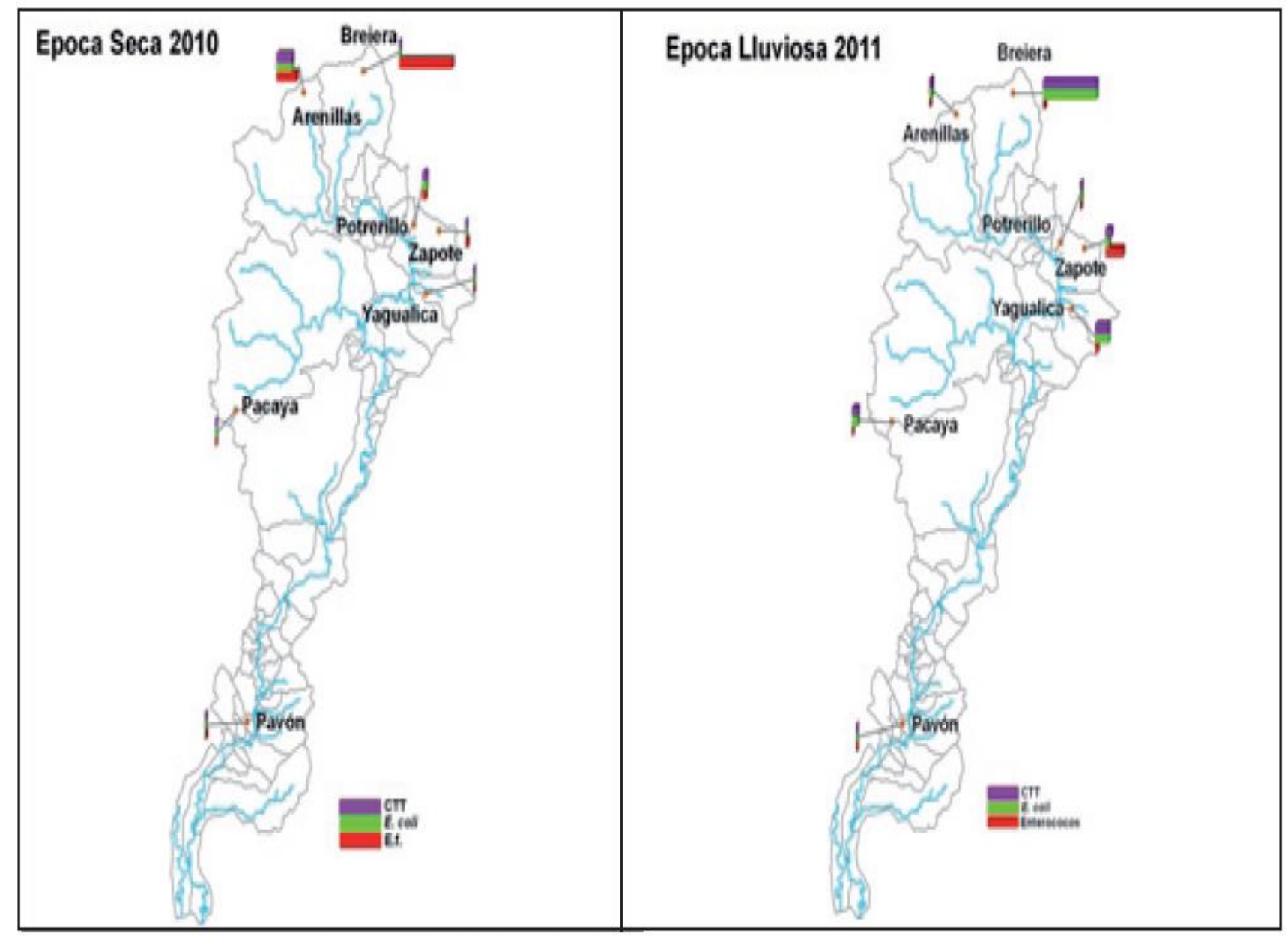

Figura 2. Indicadores de contaminación bacteriológica, en los manantiales analizados en la Subcuenca del Río Viejo para Marzo 2010 y Enero 2011.

2.00x100 y $1.30 \times 10_{2}$ NMP.100 ml-1 (fig. 2). La W.H.O, 2011, establece que bacterias E. coli o Coliformes termotolerantes, no deben ser detectadas en 100 mililitros de muestra analizada, que va a ser destinada para el consumo. Según Csuros \& Csuros (1999) E.coli es una especie indicativa de polución fecal y la posible presencia de patógenos entéricos.

En cuanto a los Estreptococos fecales, estos fueron detectados en todos los manantiales, exceptuando La

\section{Pozos Perforados}

La selección de los pozos para su estudio se basó en el criterio de que estos debían ser utilizados para el consumo de algunas comunidades de la zona. Para la época seca, los Coliformes termotolerantes y las $E$. coli estuvieron débilmente representadas. Tomabú y San José del Naranjo fueron los únicos que mostraron la presencia de éstos, en concentraciones de 9.40x101 y 1.30x10 NMP. 100 ml-1 respectivamente (ver figura 3). Contrario a 
los resultados mostrados por el grupo de los Coliformes, se observó una mayor incidencia del grupo Estreptococos fecales en esta época de estudio, estos estuvieron presentes en siete de los diez pozos examinados, en concentraciones que fluctuaron entre $2.00 \times 100$ y $4.90 \times 10_{1}$ NMP.100, según Csuros \& Csuros (1999) el grupo de los Estreptococos fecales verifica polución fecal y su presencia en el agua sugiere contaminación fecal originada por animales de sangre caliente. Santa Rosa y Tatascame, fueron los únicos exentos de la presencia de indicadores y aptos para el consumo. (ver figura 3 ).

En cuanto a la época de lluvias (Enero 2011), de los diez pozos estudiados solamente tres (Namanji, Los Arados y Santa Bárbara) se encontraron aptos para el consumo, los siete restantes presentaron densidades de Coliformes termotolerantes y de E.coli que oscilaron entre 7.80x100 y 3.30x10 1 NMP.100 ml-1 (fig.3), estas excedieron los valores guías establecidos por la W.H.O. 2011, según la cual los Coliformes termotolerantes y las E.coli no deben ser detectadas en $100 \mathrm{ml}$ de muestra analizada. Cabe destacar que en la época de lluvias, se observa una mayor incidencia de los Coliformes termotolerantes y E. coli.

Los Enterococos, solamente fueron detectados en Tomabú y Tatascame, con concentraciones de 2.00 x $10_{0}$ NMP.100 ml-1. La ausencia de éstos en la mayoría de los pozos, sugieren que la contaminación fecal observada en esta época se relaciona principalmente con material orgánico de origen antrópico. (ver figura 3).

\section{Pozos Excavados}

Las densidades bacterianas de Coliformes termotolerantes, para ambas épocas de estudio oscilaron entre $3.30 \times 10_{1}$ y $1.70 \times 10_{4}$ NMP. $100 \mathrm{ml}_{-1}$ ). Las de E. coli fluctuaron entre $3.30 \times 10_{1}$ y $1.30 \times 10_{3}$ NMP. 100 ml-1. Estas concentraciones superan los valores guías establecidos por las normas de calidad para agua de consumo humano (INAA, 2001; OPS, 1988; CAPRE, 1994). Los resultados obtenidos en los tres pozos excavados, también superan el valor máximo admisible para aguas destinadas a la irrigación, las normas canadienses establecen como concentraciones máximas tentativas, 100 Coliformes fecales (termotolerantes)/100 ml. (ver figura 4).

Los Estreptococos fecales fueron detectados en los tres pozos examinados en concentraciones que oscilaron entre 3.40 y 4.70 x 102 NMP.100 ml-1. El grupo de los Enterococos fue estudiado en la época de lluvias (Enero 2011), durante este período la máxima concentración fue detectada en Brazil Blanco 4.90x102 NMP.100 ml-1, seguido por Rosario Abajo con 2.3x10 ${ }_{1}$ NMP. 100 ml-1. En el pozo denominado Las Lagunas, no se detectó presencia de Enterococos fecales. (ver figura 4).

Aunque las normas arriba mencionadas, no incluyen a los grupos Estreptococos y Enterococos como criterio para

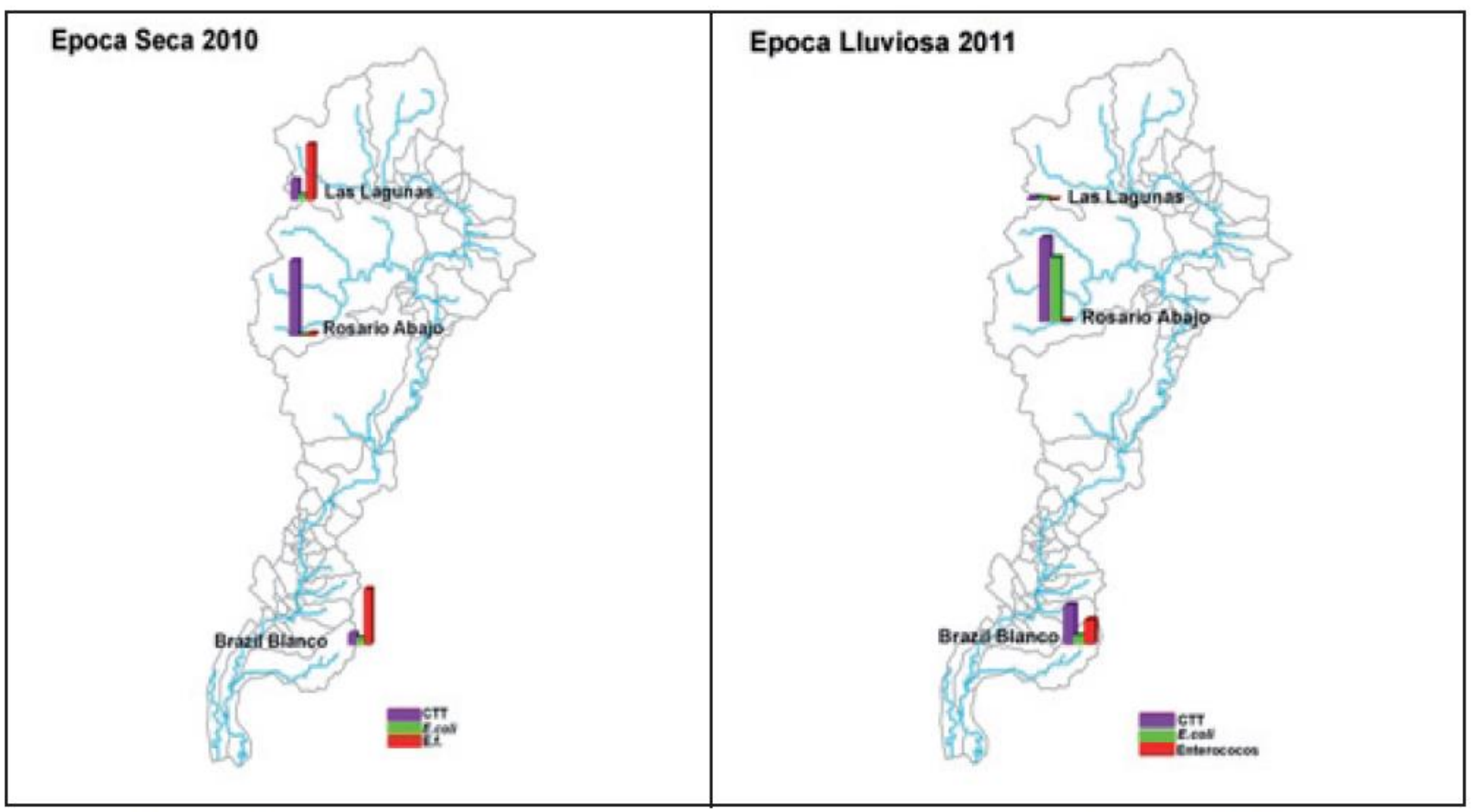

Figura 3. Indicadores de contaminación bacteriológica en los pozos perforados analizados en la Subcuenca del Río Viejo, para Marzo 2010 y Enero 2011. 
evaluar la calidad de las aguas destinadas al consumo, éstos han sido utilizados como indicadores suplementarios para evaluar la calidad sanitaria del agua y su presencia indica contaminación fecal, ya que éstos son comúnmente encontrados en las heces de humanos y otros animales de sangre caliente (APHA, 1999). cumplen con los valores guías, establecidos para aguas destinadas al consumo humano.

\section{Pozos perforados}

De los diez pozos perforados estudiados, solamente dos, en época seca (Santa Rosa y Tatascame) y tres en época de lluvia (Namanji, Los Arados y Santa Bárbara), se

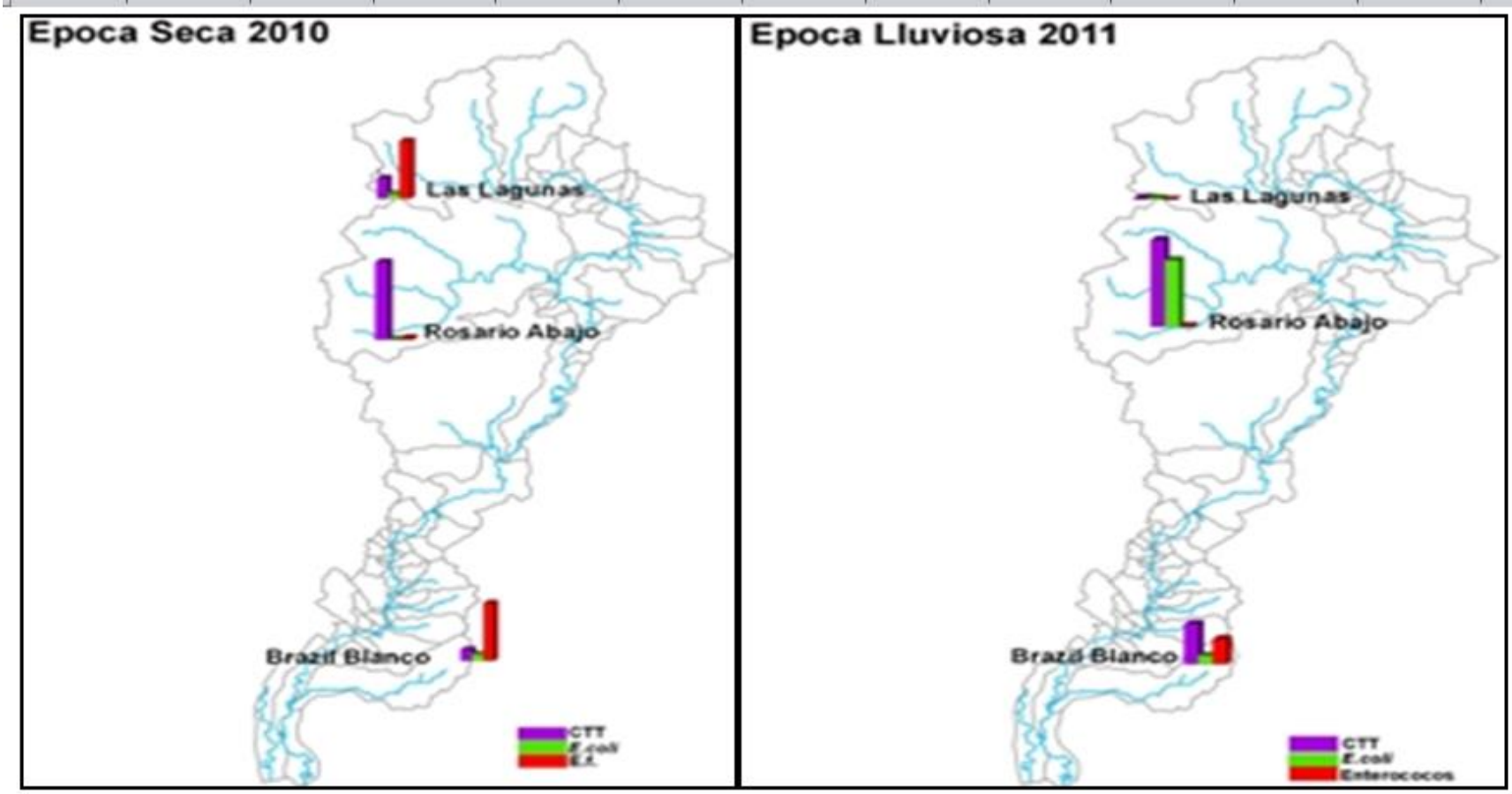

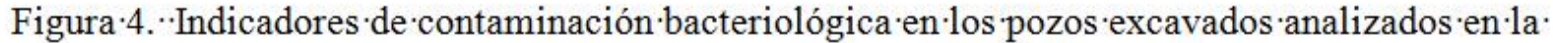
Subcuenca·del'Rio·Viejo, para'Marzo'2010·y'Enero'2011.ף

\section{CONCLUSIONES}

\section{Calidad microbiológica y sanitaria en las aguas superficiales de la Subcuenca del Río Viejo}

De los 16 sitios representativos, de las aguas superficiales, de la Subcuenca del Río Viejo, solamente dos de ellos (Lago Apanás y Abra Vieja), cumplen con los criterios establecidos por las normas internacionales, para aguas que van a ser destinadas a la recreación con contacto directo y prolongado (ejemplo natación).

En cuanto al uso de estas aguas superficiales, para riego de cultivos, según resultados obtenidos, solamente El Jordán, Lago Apanás, La Perla y Abra Vieja, cumplen con el valor guía establecido por las normas Canadienses (100 Coliformes fecales/100 ml).

Calidad microbiológica y sanitaria en las aguas subterráneas de la Subcuenca del Río Viejo

\section{Manantiales}

De los siete manantiales estudiados, solamente La Pacaya, en época seca y El Pavón, en época lluviosa, encontraron aptos para el consumo humano.

\section{Pozos excavados}

Los tres pozos excavados que se evaluaron, superan los valores guías establecidos por las normas de calidad para aguas destinadas al consumo humano, es decir que no son aptos para consumo y representan un potencial riesgo a la salud de quienes la consumen.

Los Estreptococos fecales se detectaron en todos los pozos estudiados en concentraciones que oscilaron entre $3,40-4,70 \quad \mathrm{x} \quad 10_{2} \quad \mathrm{NMP} / 100 \mathrm{ml}$, lo que sugiere contaminación por desechos orgánicos de origen animal.

Los resultados obtenidos, evidencian que las aguas superficiales y subterráneas, están siendo influenciadas por actividades de origen antrópicas y que existe una contaminación de origen fecal, que representa un riesgo potencial a la salud de la población.

\section{RECOMENDACIONES}

Desarrollar programas de Control y Vigilancia, para las aguas superficiales que drenan sobre el Río Viejo. 
Ejecutar campañas educativas, relacionadas con la problemática de salud y el consumo de agua no potable.

Promover cambios en la conducta ciudadana, a través de campañas educativas, para el buen uso y aprovechamiento del agua, así como la adecuada disposición de la basura y de las aguas residuales generadas en la zona.

Mejorar la infraestructura de los pozos y de la captación de los manantiales

\section{BIBLIOGRAFÍA}

American Public Health Association (APHA) 1999. Standard Methods for the Examination of Water and Wastewater. 20st. Ed. Washington: APHA

American Public Health Association (APHA) 2005. Standard Methods for the Examination of Water and Wastewater. 21 st. Ed. Washington: APHA

Comité Coordinador Regional de Instituciones de Agua Potable y Saneamiento de Centroamérica, Panamá y República Dominicana (CAPRE). (1994). Normas de Calidad de Agua para Consumo Humano Costa Rica: CAPRE.

Csuros, M \& C. Csuros, 1999. Microbiological Examination of Water and Wastewater. Lewis Publishers, New York.

European Economic Committee (EEC) (1976). Council directive of 8 December 1975 concerning the quality of bathing water. Official Journal of the European Communities. $\quad 19$ : $\quad$ L 31 . http://www.marena.gob.ni/index.php?option=com

content\&task=view\&id=236\&Itemid=586. Recuperado el 30 de Agosto del 2012.

Instituto Nicaragüense de Acueductos y Alcantarillados (INAA). (2001) Normas técnicas para el diseño de abastecimiento y Potabilización del Agua. Managua: INAA-Ente Regulador.

Organización Panamericana de la Salud (OPS). 1988. Guías Para la Calidad del Agua Potable. Volumen 3. Control de la calidad del agua potable en sistemas de abastecimiento para pequeñas comunidades.

U.S.EPA (U.S. Environmental Protection Agency). 1986. Ambient Water Qualityy Criteria for Bacteria-EPA 440-5-84002.
World Health Organization (W.H.O). 2011. Guidelines for drinking-Water Quality, fourth edition. Geneva 27, Switzerland: W.H.O. 